\title{
Studying Nonverbal Synchrony in Couple Therapy-Observing Implicit Posture and Movement Synchrony
}

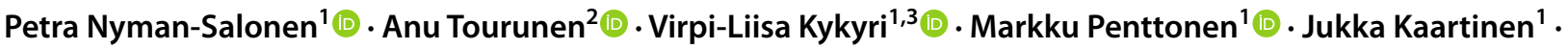 \\ Jaakko Seikkula ${ }^{1}$
}

Accepted: 27 October 2020 / Published online: 25 November 2020

(c) The Author(s) 2020

\begin{abstract}
Research on nonverbal synchrony (movement coordination) in psychotherapy has recently attracted increased attention. Nonverbal synchrony has been shown to relate to the therapeutic alliance and outcome. However, research on nonverbal synchrony in couple therapy remains scarce. In this study, we examined the therapy process of one couple in detail and created a coding scheme to depict posture and movement synchrony. In this case study, we found that the relationship between nonverbal synchrony and the therapeutic alliance was complex. During the therapy process, the amount of nonverbal synchrony varied, as did the participants' evaluations of the alliance. In couple therapy nonverbal synchrony could affect both the persons involved in it and the persons observing it. In one of the sessions, almost all the synchronies occurred between the female client and one of the therapists, and all except the female client evaluated the alliance to be weaker. In this case study, there were two therapists present, and the co-therapists' synchrony was found to be important for the male client's evaluations of the alliance. When there was more synchrony between the therapists, he evaluated the alliance to be stronger. Interestingly, the co-therapists' synchrony seemed to peak in sessions that succeeded sessions with a weaker alliance, as if the therapists were implicitly making a joint effort to strengthen the alliance. A short episode from one session is given to illustrate the findings. Our coding scheme enables studying nonverbal synchrony (posture and movement synchrony) in couple therapy and combining the research results to other temporally precise data obtained from the sessions. More research is needed to validate the method.
\end{abstract}

Keywords Nonverbal synchrony $\cdot$ Posture synchrony $\cdot$ Movement synchrony $\cdot$ Couple therapy $\cdot$ Mimicry $\cdot$ Alliance

\section{Introduction}

Nonverbal synchrony is the tendency of participants to implicitly synchronize their behaviors to each other during interaction. Nonverbal synchrony has been studied using various methods (cf. Bavelas et al. 1986; Bernieri et al. 1988; Cornejo et al. 2017; Kimura and Daibo 2006), different terminology (interpersonal coordination, behavioral

Petra Nyman-Salonen

petra.nyman-salonen@jyu.fi

1 Department of Psychology, University of Jyväskylä, P.O. Box 35, 40014 Jyväskylä, Finland

2 The Gerontology Research Center, Faculty of Sport and Health Sciences, University of Jyväskylä, Jyväskylä, Finland

3 Faculty of Social Sciences/Psychology, University of Tampere, 33014 Tampere, Finland synchrony, interpersonal synchrony, mimicry, matching, alignment, etc.), and in different contexts, including psychotherapy (Altmann et al. 2019; Ramseyer and Tschacher 2011).

In psychotherapy, nonverbal synchrony has been shown to be related to the therapeutic outcome: the more synchrony there is between therapist and patient, the better the outcome (Ramseyer and Tschacher 2011). The more head movement synchrony there is, the better the global outcome of the therapy, whereas more upper-body movement synchrony is related to better evaluations of the sessions (Ramseyer and Tschacher 2014). Earlier research has shown that there is more nonverbal synchrony in sessions that the therapists or an outside expert evaluate to be of high quality (Nagaoka and Komori 2008).

Recently, Ramseyer (2020) showed that the relationship that nonverbal synchrony has with alliance and outcome is not as straightforward as the nomothetic research done with 
large samples (i.e., Ramseyer and Tschacher 2011, 2014) has suggested. A study of the intraindividual variation (i.e., using an idiographic perspective) in a limited number of therapy cases showed that sessions characterized by little progress were marked by high synchrony, and patients showing higher levels of synchrony across therapy sessions tended to report more interpersonal problems (Ramseyer 2020). Similarly, Paulick et al. (2018) showed that the highest amount of nonverbal synchrony between therapist and patient was related to non-improving patients, whereas an intermediate level of nonverbal synchrony was related to patient improvement and low levels of synchrony to patient dropout. These results are important since they show that it is too simplistic to think that more synchrony is always better in the context of psychotherapy.

Interestingly, research on nonverbal synchrony in couple therapy remains scarce, despite the importance accorded to paying attention to nonverbal communication patterns in couples (Gottman and Porterfield 1981). Synchronization of immediacy behaviors (i.e., gaze direction, body openness, distance, touching, and body position), which are said to regulate the intimacy between partners, has been shown to be more prevalent in satisfied couples (Julien et al. 2000).

The readiness to interact or engage in the couple therapy process has been studied using the Body Formation Coding System, which assesses engagement at the triadic level between the therapist and the couple (de Roten et al. 1999). The method focuses on how participants include or exclude others in couple therapy, i.e., how they turn toward or away from each other or lean forward or backward. It does not study synchrony per se. De Roten et al. (1999) found that the therapeutic alliance was not related to any kind of exclusion or inclusion pattern in the body formations; rather, a good therapeutic alliance occurred when participants engaged in predictable ways with each other, creating recurring patterns of engagement.

It should be noted that the relationship between the alliance and the outcome is generally more complex in couple therapy than in individual psychotherapy (cf. Friedlander et al. 2011); the relationship between evaluations of the alliance and the outcome may also differ even without the added complexity of nonverbal synchrony. According to some studies with heterosexual couples, the male client's evaluation of the alliance is more strongly related to the outcome than the female client's evaluations (Bourgeois et al. 1990; Symonds and Horvath 2004).

The System for Observing Family Therapy Alliance, hereafter SOFTA (Friedlander et al. 2006), is a method developed to observe alliances in family and couple therapy. The method focuses on a range of behaviors, including nonverbal behaviors, as markers of the alliance. The coding scheme does not include synchrony of nonverbal behavior, except for posture synchrony, i.e., implicit imitation of postures, which is considered in SOFTA to be a sign of emotional contact and a shared sense of purpose within the family.

Posture synchrony (also called congruence or mirroring) in psychotherapy has been shown to be related to the rapport between therapist and patient (Tickle-Degnen and Rosenthal 1990; Trout and Rosenfeld 1980); greater posture synchrony has been observed in moments of high rapport in a therapy session (Sharpley et al. 2001). Posture synchrony has also been shown to be related to empathy: when the therapist imitates the patient's posture, the therapist is perceived to be more empathic (Maurer and Tindall 1983). In case studies of psychotherapeutic processes, posture synchrony has been shown to occur implicitly (Davis and Hadiks 1994) and in important moments of a therapy session (Raingruber 2001).

According to research on nonverbal synchrony in psychotherapy and SOFTA, as well as research on posture synchrony, it seems plausible that implicit nonverbal synchronization between the participants in couple therapy could be associated with the therapeutic alliance.

\section{Nonverbal Synchrony-A Prosocial Glue}

The influence of nonverbal synchrony on relationships has been extensively studied in various fields of research (cf. Chartrand and Lakin 2013). For the present study, findings from two fields are relevant: research on nonverbal synchrony, or movement coordination between participants, and research on mimicry, i.e., implicit imitation of physically similar movements. A meta-analysis on nonverbal synchrony showed that it has a robust positive effect on relationships (Vicaria and Dickens 2016). A review of mimicry research reached a similar conclusion, showing that mimicry has prosocial effects (Chartrand and Lakin 2013): it fosters liking (Chartrand and Bargh 1999) and rapport (Lakens and Stel 2011) and increases when the participants' goal is to affiliate with others (Lakin and Chartrand 2003).

Mimicry has been related to empathy as well. People who are more empathic tend to implicitly imitate others more (Chartrand and Bargh 1999; Sonnby-Borgström 2002; Sonnby-Borgström and Jönsson 2003). The tendency to imitate others has been called a primitive or bodily form of empathy (de Waal 2007), where imitating another person's behavior engenders a better understanding of the other's experience (Chartrand and Lakin 2013). It has been suggested that through implicit imitation, one strives to attune to the other's internal state (Chartrand and Lakin 2013; Davis and Hadiks 1994; Stel and Vonk 2010). Based on her case study, Raingruber (2001) suggested that in psychotherapy, therapists strive to understand and "be with" the client and develop a mutual sense of connection through synchronizing their nonverbal behavior with that of the client. 
Two theoretical frameworks have been put forth concerning nonverbal synchrony (i.e., movement coordination). Baimel et al. (2015) suggested that nonverbal synchrony prepares us for engaging with the mental world of others and enhances our understanding of others through various cognitive processes. Koole and Tschacher (2016) developed the Interpersonal Synchrony model of nonverbal synchrony in psychotherapy, in which they grounded the therapeutic alliance in the nonverbal synchrony or coordination between therapist and patient. According to them, nonverbal synchrony facilitates an understanding of the other's experiences and emotions through coupling of the therapist's and patient's brains, which may over time improve patients' capacity for the regulation of emotion.

Here, we studied nonverbal synchrony in couple therapy, a context in which nonverbal synchrony patterns are more complex as the context involves multiple participants and multiple relationships, i.e., the relationship between the spouses (allegiance), the relationship between the clients and the therapist(s), and in this case, the relationship between the two participating therapists. This introduces a novel aspect into nonverbal synchrony: those who are not participating in nonverbal synchrony but are watching it may also be affected by it. This question was addressed in our study by investigating the associations of nonverbal synchrony patterns observed with the participants' evaluations of the therapeutic alliance.

\section{Methods Used to Study Nonverbal Synchrony}

Our aim was to study nonverbal synchrony, especially implicit imitation of postures and movements, from authentic videos of couple therapy. To choose the research method, earlier methods used to study nonverbal synchrony were assessed. Two main methods were used in previous studies: observation and automated frame-differencing.

Observation is the method most commonly used (cf. Hall et al. 1995). Observation requires that trained raters evaluate the presence of predefined behaviors, which form the coding scheme. The methodology of observation varies: the raters can (1) name the most frequently occurring nonverbal behavior within a certain time interval, for instance, within 30 s (cf. Davis and Hadiks 1994; LaFrance 1985); or (2) evaluate the number of predefined behaviors in a segment of interaction (cf. Bernieri et al. 1988). The raters can also use behavioral ratings, i.e., the behavior is evaluated using a Likert-scaled questionnaire for evaluation (see Bavelas et al. 1986, for a detailed methodological paper on observational methods used in mimicry research). The frequency or occurrence of nonverbal behaviors at the exact moment they happen is not usually coded, thus emphasizing the observer's evaluation. Exceptions are the studies on nonverbal behavior conducted by Davis and Hadiks (1990, 1994), in which they coded postures of therapists and clients separately; the studies did not look at nonverbal synchrony between the participants.

Observational data often results in nominal data, which is more difficult to analyze. Louwerse et al. (2012) presented a method for calculating nonverbal synchrony of nominal observational data by using cross-recurrence analysis. Such analysis reveals the temporal dynamics of the observational data and compares the recurrence of behaviors between two participants (i.e., synchrony).

All observational methods share the disadvantage that they are time-consuming and require trained raters. To shorten the data observation process, automated video analysis methods have been used (cf. Nagaoka and Komori 2008; Ramseyer and Tschacher 2011, 2014). These automated frame-differencing methods, such as motion energy analysis (MEA), mark the change in pixels between video frames as movement. With these methods, all movements in predefined regions of interest (e.g., head and trunk) are studied. Synchrony is then calculated based on these pixel changes. The estimate of nonverbal movement synchrony thus refers to any kind of simultaneously occurring movement within the region of interest. The physical appearance or shape of the movement is not considered. By using this method, head movement synchrony occurs even when one person shakes his head and the other one nods. Within the context of psychotherapy as a meaning-making process, this seems somewhat odd.

To test whether automated methods do indeed produce satisfactory results, Fujiwara and Daibo (2014) compared an automated method for detecting nonverbal behaviors to traditional coding and behavioral rating methods. They found that the automated method correlated to traditional coding and behavioral ratings. They concluded that automated methods are potentially more valuable since they are costeffective and reduce the need to train skilled raters. For an extended review of methods used in studying interactional synchrony, see Kimura and Daibo (2006).

Even though the traditional method of observation is more time-consuming, it was chosen for this study because no automatic method to date has been capable of identifying the imitation of similar postures and movements (mimicry) from videos. The automated methods available are not suitable for analyzing sessions as lengthy as the studied psychotherapy sessions were, and they usually use servers that are not secure enough to ensure the privacy of the couple in therapy. Thus, no method that stored the data on a server outside the university could be used. Frame-differencing methods were not chosen because they are unable to discriminate between similar and dissimilar movements within the region of interest and do not capture instances of static posture synchrony. 
Another important aspect was that the coding scheme developed here needed to mark the nonverbal synchrony of behaviors at the exact time they occurred in the session. This was important since one aim was to use the observational data in combination with other temporally exact data obtained from the session, such as autonomic nervous system reactions or spoken dialogue. Frame-differencing methods are usually not used in such a time-exact manner; thus, they were not considered (time windows are usually about $10 \mathrm{~s}$ ). It was necessary to develop a coding scheme of posture and movement synchrony to be used in the context of couple therapy.

\section{Summary}

On the basis of prior research, it can be concluded that nonverbal synchrony affects the relationship between the participants. In the context of couple therapy, nonverbal synchrony has not been studied much. According to earlier research and theoretical models of nonverbal synchrony, posture synchrony and mimicry facilitate the understanding of others and create liking and rapport between participants.

The observational method was chosen even though it is time-consuming because the frame-differencing methods lose qualitatively important aspects of nonverbal synchrony. For the present study, we observed and reported the results from one couple therapy process in detail; during development, other couple therapy cases were also observed.

The research aims were: (1) to develop a coding scheme for looking at nonverbal synchrony (especially implicit imitation of nonverbal behavior that is similar in physical appearance) in the context of couple therapy by using qualitative observation of therapy sessions; and (2) to investigate how the observed nonverbal synchrony patterns were related to the therapeutic alliance in a therapeutic process of one couple. A short episode selected from a session will illustrate one incident of nonverbal synchrony.

\section{Method}

\section{Design, Participants, and Data Selection}

The data analyzed here was selected from a pool of data that was collected in the Relational mind in events of change in multiactor therapeutic dialogues research project at the University of Jyväskylä (Seikkula et al. 2015). The therapy was conducted in a natural couple therapy setting with two therapists present. The presence of two therapists is the established way to work in couple therapy in the facility. The therapy was not manualized; rather, narrative and dialogical approaches were used. The therapy did not include any bodily interventions. The therapy sessions were recorded with six cameras. Four cameras focused on the participants' faces (one on each participant), and two cameras recorded the full bodies of dyads, one dyad being the couple and the other dyad the therapists. In this study, videos were used that showed the full bodies of the four participants in a split-screen format.

Since one aim of the research project was to study the synchrony of autonomous nervous system reactions, such reactions in the participants were recorded in the second and sixth sessions. For this purpose, heart rate monitors were attached to each participant's chest, two skin conductance electrodes were attached to the palm of each participant's non-dominant hand, and a respiration rate fabric belt was fastened around each participant's lower chest. The skin conductance measurement equipment was attached to the chair in which the participant sat, meaning that it restricted the movements of the non-dominant arm to a range of approximately $25 \mathrm{~cm}$ from the chair. Since the aim of the research project was to study the autonomous reactions of the participants and the interest in looking at the nonverbal synchrony between the participants developed only after the therapies had commenced, this meant that neither the therapists nor the clients were aware that their bodily movements would be analyzed.

Each therapy session lasted approximately $90 \mathrm{~min}$. The therapeutic alliance was monitored using the Session Rating Scale (SRS), which was given to both the clients and the therapists after each session (Duncan et al. 2003). SRS is a visual analogue self-report measure that uses a Likerttype scale. It is an alliance measurement scale developed on the basis of Bordin's (1979) theory of alliance, which emphasizes the relational bond and agreement on goals and tasks. The ultra-brief version of SRS was used, which comprises four items depicting the four different aspects of alliance (Duncan et al. 2003). The "Relationship" scale assesses the statement, "I felt/did not feel heard, understood, and respected" and the "Goals and Topics" scale assesses the statement, "We worked on or talked about/ did not work or talk about what I wanted to work on or talk about." The "Approach or Method" scale requires rating the session to assess the statement, "The therapist's approach is/is not a good fit for me." The fourth item rates the overall session to assess the statement, "There was something missing in the session today" vs. "Overall, today's session was right for me." It is important to note that the clients evaluated the co-therapists as a team while the therapists evaluated the alliance in relation to both spouses simultaneously.

The research procedure was approved by the University of Jyväskylä Ethical Committee, and all participants gave their written informed consent to participate in the research project. The design and data collection were performed by Kaartinen, Kykyri, Penttonen, Tourunen, and 
Seikkula. The coding scheme was developed by the first author Nyman-Salonen.

To develop the present coding scheme, the therapy process of one couple was examined. The couple was chosen since their therapy videos were available for analysis when the development of the coding scheme commenced. The process comprised ten sessions, nine of which (sessions 2-10) were analyzed. The first session was unfortunately omitted from analysis due to technical problems in the video recording. In two of the analyzed sessions (sessions 2 and 6), both the therapists and the clients wore autonomic nervous system measurement equipment.

\section{The Case}

The couple came to therapy because of loyalty issues in their relationship; in addition, the husband had previously behaved violently toward his wife. Couple therapy was recommended; no violence occurred during the time the couple was in therapy. The wife was pregnant at the beginning of the therapy process, and the baby was born in the middle of it. The baby was present in some of the analyzed sessions. Most of the time, the baby was in a baby car seat on the floor, but if the baby started crying during the session, the parents held her on their laps. The two male therapists working with this couple were both experienced couple and family therapists.

\section{The Procedure: Qualitative Analysis of Videotapes for the Development of the Coding Scheme}

To begin the development of the observational coding scheme, the first author systematically observed the aforementioned videotaped sessions. This was done without sound so that the dialogue would not influence the interpretation of the nonverbal behavior. The videos showed the full bodies of the participants in a split-screen format; the videos of the participants' facial expressions were not used because our interest was to study the nonverbal synchrony of the participants' body postures and movements. Furthermore, facial expressions might have influenced the interpretation of nonverbal behavior. In the full-body videos, the facial expressions of the participants were not clearly visible due to the distance of the camera from the participants and the layout of the split-screen video, which showed both the couple and the therapists. In the software used for observation, the screen showing the videotapes had to be quite small to enable the observers to see all four participants simultaneously in order to detect nonverbal synchrony.

The aim was to look at instances of nonverbal synchrony, i.e., instances in which a participant implicitly imitated the other's postures or movements. The qualitative analysis aimed at creating a categorical coding scheme.
As the aim was to create a replicable method that others could use, specific notes were taken on the precise definition of the various categories of implicit imitation. This meant that the most important criterion of nonverbal synchrony was the physical similarity of implicitly imitated postures and movements. This minimized observer bias by reducing the amount of evaluation the observers were required to perform. During the observational process, decisions on what to include in and exclude from the coding scheme were made and discussed with other observers (see "Interrater reliability" below). For instance, the abovementioned presence of the baby in the sessions was discussed; it was jointly decided how to take the baby's presence into account during the observations. The observations were carried out using the Noldus Observer program (two versions, 11.5 and 12.5, were used due to a software update that occurred during the research process; www.noldus.com).

\section{Interrater Reliability}

The method was tested for interrater reliability. All the sessions were rated by the first author. Four additional observers (hereafter "raters"), who were undergraduate students in the Psychology department, rated two sessions each (session 3 was rated by the author and two raters, session 6 by the author and two other raters, and session 10 by all the raters). All raters were trained in using the observational method and observed the sessions without sound. The training began with a presentation of the method and coding scheme, after which the raters observed 10 min of one therapy session in pairs and discussed the observational method together and with the first author. After the observation, the two pairs' results were compared with the first author's observations and disagreements were discussed. After this, the raters observed one session individually; the observations were then discussed, first pairwise, and then with the first author. If the raters encountered unclear instances, they noted these for discussion during the observations. Some unclear instances occurred when the baby was in either of the parents' laps; it was agreed that the overall physical appearance of the parent, meaning how the parent held his or her arms and legs during that time, should be compared to the other participants' postures to check for posture synchrony.

Interrater reliability was obtained using the Noldus Observer program (version 12.5), based on the frequency and sequence of the behaviors observed in time intervals of $3,2,1$, and $0.5 \mathrm{~s}$. The Observer program calculates pairwise interrater reliability, an Index of Concordance, and the percentage of agreements as well as Cohen's Kappa, Pearson's Rho, and the Prevalence index (stating the degree to which 
the number of agreements in one variable is higher than in another variable).

\section{Statistical Analysis}

Statistical analysis was performed to examine whether the frequency of the nonverbal synchrony behaviors differed across sessions and whether wearing the measurement equipment had an impact on the frequency of nonverbal synchrony (measurement equipment was worn only in the second and sixth sessions). Analysis was performed using generalized estimated equations (GEE) with a non-parametric Poisson log-linear model. GEE is an extension of the general linear model but is suitable for use with longitudinal data (the same participants in a repeated-measures fashion) when the cases are not independent (Wang 2014). The statistical analysis was performed using IBM SPSS Statistics version 24.

\section{Qualitative Analysis of Nonverbal Synchrony Patterns and the Therapeutic Alliance}

The therapy process was first analyzed separately for nonverbal synchrony patterns and the participants' evaluations of the alliance on the SRS. After this, the observations of posture and movement synchrony patterns in the sessions and the alliance evaluations were triangulated. ${ }^{1}$ An episode illustrating how posture synchrony manifested itself in the session is presented.

\section{Results}

First, the qualitative developmental process used for the coding scheme will be described, and the interrater reliability obtained using it will be presented. Second, the descriptives of the nonverbal synchronies will be shown. Third, the statistical analysis performed on the data obtained by comparing the nonverbal synchronies among the sessions will be presented. Fourth, the qualitative analysis of the therapeutic process triangulating the posture and movement synchronies observed with the participants' evaluations of the alliance will be presented. Finally, an episode of one session will be presented in which posture synchrony occurs between two of the participants.

\footnotetext{
1 The relationship between posture and movement synchrony to the therapeutic alliance was also calculated by calculating bootstrapped confidence intervals (95\%) for the nonparametric correlations between the nonverbal synchrony behaviors per subject and alliance measurements of the session (SRS). The subscales (Relationship, Goals and Topics, Approach or Method, and Overall) and the sum of the subscales were used. The results are provided in "Appendix 2".
}

\section{Qualitative Observation Process for Developing the Coding Scheme}

The first qualitative observation was that the participants in the couple therapy sessions sat quite still. Mainly speech-related gesturing, nodding, posture shifting, arm movements, and directing the gaze were observed. Two main categories of synchrony were observed: posture synchrony and movement synchrony.

Posture synchrony and movement synchrony were separated into two different categories because of their temporal differences. Posture synchrony, in which one person imitated another participant's posture, was a state event, meaning it had duration and lasted for some time until one of the participants left the shared posture. In contrast, imitation of movement was considered a point event, where only the frequency was calculated.

The categories were further elaborated. Posture synchrony was defined as two or more participants sharing a similar posture with their torso, legs, and arms. The most important criterion was that the physical positions of the bodies and the limbs had to be similar. Posture synchrony was not restricted to mirror images of the others' postures, as congruent postures were also included (the right arm and leg of person A matching the right arm and leg of person B). Previous research indicated that the felt difference between these is not relevant for the participant (Raingruber 2001).

Movement synchrony was defined as occurring when two or more participants made a similar movement with the same body part within a time interval of $3 \mathrm{~s}$. The interval used in mimicry research varies from 3 to $8 \mathrm{~s}$ (Chartrand and Lakin 2013). An interval of $3 \mathrm{~s}$ was chosen based on research showing that shorter intervals of mimicry are more easily felt to be mimicry (Bailenson et al. 2004) and following a discussion with a senior researcher in the area of neuroscience Markku Penttonen.

Movement synchrony was further divided into subcategories based on the body parts involved: head, arm, hand, torso, and legs. A category named "other" was created because some synchronized movements were functional (e.g., picking up something or sighing) and did not fit into the body part subcategories. The most important criterion for movement synchrony was that the shape of the movement made by two, three, or four participants had to be similar. The similarity was defined by stating that the synchronized movements made by the participants had to start from the same position, make a similar movement in form, and end in the same position. For instance, head movements in which one participant nodded, i.e., moved their chin down and up, and the other participant only put their chin down, was not considered to be head movement synchrony because the end of the movement was dissimilar. The size of the movement was not precisely defined, but the movement had to be visible to the observer's eye to be included. 
Table 1 Coding scheme for observing nonverbal synchrony

\begin{tabular}{ll}
\hline Behavior & Operational definition \\
\hline Posture synchrony & $\begin{array}{c}\text { Two or more participants being in a similar posture with their arms and legs, such as both arms on the armchairs } \\
\text { with their hands facing in a similar direction and with their legs crossed }\end{array}$ \\
Head movement synchrony & $\begin{array}{c}\text { Two or more participants making the same head movement within a 3-s interval, such as nodding } \\
\text { Two or more participants making the same movement with their arms (from the shoulder to the hand), where the } \\
\text { peak of the movement occurs within a 3-s interval, such as touching their face with their hands }\end{array}$ \\
Torso movement synchrony & $\begin{array}{c}\text { Two or more participants making the same movement with their torsos within a 3-s interval, such as stretching the } \\
\text { torso } \\
\text { Hand movement synchrony }\end{array}$ \\
$\begin{array}{c}\text { Two or more participants making the same movement with their hands within a 3-s interval, such as clapping their } \\
\text { thighs } \\
\text { Two or more participants making the same movement with their legs within a 3-s interval, such as crossing their } \\
\text { legs }\end{array}$ \\
Other movement synchrony
\end{tabular}

The subcategories were mainly created to enable examining the sessions in greater detail and were not used here for statistical testing. The coding scheme and definitions are shown in Table 1.

The subject structure of the method differed from that of earlier methods (see Table 2). During observations, it was noted that synchrony occurred between a dyad, triad, and even a tetrad of participants. It was decided that the various combinations of participants would be used as synchrony groupings. This meant that of the four participants, six dyads were created: the couple (A B), the therapists (T1 T2), and one of the therapists with one of the clients (T1 A, T1 B, $\mathrm{T} 2 \mathrm{~A}$, and $\mathrm{T} 2 \mathrm{~B}$ ). In addition, four triads were created: the therapists and one of the clients (T1 T2 A, and T1 T2 B), and one of the therapists and the couple (T1 A B and T2 A $\mathrm{B}$ ), and finally, one tetrad that included all participants (T1 T2 A B). These combinations were used as subjects. Thus, synchrony was coded only for the synchrony groups (i.e., $\mathrm{T} 2 \mathrm{~A}$ in posture synchrony) and individual coding (i.e., T2 nodding) was not used.

\section{Interrater Reliability for Session Coding}

Interrater reliability for the session coding was obtained using the Noldus Observer program, version 12.5. The results were calculated using tolerance windows of 3, 2, 1, and $0.5 \mathrm{~s}$. The results of the 1 -s tolerance window are presented here. The overall Index of Concordance was 0.85, the percentage of agreement was $84.5 \%$, Cohen's Kappa was 0.84 ( $\mathrm{p}<0.001)$, Cohen's Kappa max was 0.95, and Pearson's Rho was $0.99(\mathrm{p}<0.001)$. The prevalence index was 0.9 . These results show that interrater reliability was nearly perfect (Landis and Koch 1977). The respective results using a tolerance window of $0.5 \mathrm{~s}$ were $0.7,71.2 \%, 0.7,0.93$, and 0.98 , which were all also very high.

\section{Descriptives of Posture and Movement Synchrony}

During the nine analyzed sessions, the frequency of the different nonverbal synchronies varied. Posture synchrony occurred on average 30.22 times during a session (SD 10.63; $\min =13, \max =47)$ and movement synchrony occurred 93.78 times (SD 29.30; $\min =55, \max 152$ ). The mean, standard deviation, minimum and maximum values, and the total value of posture synchrony per synchrony group for the nine sessions combined is presented in Table 3; the data for movement synchrony is presented in Table 4 .

Tables 3 and 4 indicate that for some of the synchrony groupings, there were sessions in which no synchrony occurred. Qualitative inspection reveals that posture synchrony occurred especially between therapist 2 and female client (A), between therapist 2 and the male client (B), between therapist 1 and the male client (B), and between the co-therapists (Table 3). Movement synchrony occurred mostly between the co-therapists and between therapist 2 and the female client (A) (Table 4). The movement

Table 2 Synchrony groupings

\begin{tabular}{ll}
\hline A B & $\begin{array}{l}\text { The couple, A sitting on the right and B on the left } \\
\text { T1 T2 }\end{array}$ \\
$\begin{array}{ll}\text { The therapists, T1 sitting on the left and T2 sitting on } \\
\text { the right }\end{array}$ \\
T1 A & Therapist 1 and client A (sitting opposite each other) \\
T1 B & Therapist 1 and client B (sitting diagonally to each other) \\
T2 A & Therapist 2 and client A (sitting diagonally to each other) \\
T2 B & Therapist 2 and client B (sitting opposite each other) \\
T1 A B & Therapist 1 and client A and B \\
T2 A B & Therapist 2 and client A and B \\
T1 T2 A & Therapists and client A \\
T1 T2 B & Therapists and client B \\
T1 T2 A B & All participants
\end{tabular}


Table 3 Posture synchrony per synchrony group during nine sessions

\begin{tabular}{llllllllllll}
\hline & T1T2 & T1A & T1B & T2A & T2B & AB & T1T2A & T1T2B & T1AB & T2AB & T1T2AB \\
\hline$M$ & 4.22 & 0.00 & 6.22 & 11.44 & 5.44 & 2.22 & 0.00 & 0.22 & 0.00 & 0.44 & 0.00 \\
$S D$ & 6.20 & 0.00 & 4.41 & 8.23 & 5.23 & 2.28 & 0.00 & 0.44 & 0.00 & 0.73 & 0.00 \\
Min & 0 & 0 & 1 & 0 & 0 & 0 & 0 & 0 & 0 & 0 & 0 \\
Max & 20 & 0 & 16 & 22 & 16 & 6 & 0 & 1 & 0 & 2 & 0 \\
Sum & 38 & 0 & 56 & 103 & 49 & 20 & 0 & 2 & 0 & 4 & 0 \\
\hline
\end{tabular}

$N=9$

$T 1$ therapist 1,T2 therapist 2, $A$ female client, and $B$ male client

\begin{tabular}{llllllllllll}
\hline & $\mathrm{T} 1 \mathrm{~T} 2$ & $\mathrm{~T} 1 \mathrm{~A}$ & $\mathrm{~T} 1 \mathrm{~B}$ & $\mathrm{~T} 2 \mathrm{~A}$ & $\mathrm{~T} 2 \mathrm{~B}$ & $\mathrm{AB}$ & $\mathrm{T} 1 \mathrm{~T} 2 \mathrm{~A}$ & $\mathrm{~T} 1 \mathrm{~T} 2 \mathrm{~B}$ & $\mathrm{~T} 1 \mathrm{AB}$ & $\mathrm{T} 2 \mathrm{AB}$ & $\mathrm{T} 1 \mathrm{~T} 2 \mathrm{AB}$ \\
\hline$M$ & 30.44 & 6.89 & 9.33 & 22.11 & 9.67 & 6.22 & 1.56 & 1.89 & 2.78 & 1.56 & 1.33 \\
$S D$ & 12.3 & 3.3 & 3.61 & 13.08 & 4.64 & 4.79 & 1.67 & 2.26 & 2.17 & 2.83 & 1.73 \\
Minimum & 12 & 2 & 2 & 6 & 3 & 1 & 0 & 0 & 0 & 0 & 0 \\
Maximum & 52 & 13 & 14 & 41 & 18 & 14 & 5 & 6 & 6 & 9 & 5 \\
Sum & 274 & 62 & 84 & 199 & 87 & 56 & 14 & 17 & 25 & 14 & 12 \\
\hline
\end{tabular}

$N=9$

$T 1$ therapist 1,T2 therapist 2, $A$ female client, and $B$ male client
Table 4 Movement synchrony per synchrony group during nine sessions synchronies consisted mostly of head nods (59\% of all movement synchronies). It is noteworthy that nonverbal synchrony between the couple was not that frequent. All frequencies of posture and movement synchrony per synchrony group for each session are presented in Appendix 1.

\section{Statistical Analysis}

\section{The Difference in Nonverbal Synchrony Between Sessions}

The differences in the frequencies of postures and movements per session were calculated using GEE and a Poisson log-linear model. Pearson residuals over an absolute value of 2.0 were considered to deviate significantly from the estimated model.

Posture synchrony was significantly higher than the estimated mean in sessions 2 and 9 (Pearson residual 2.506 and 3.052 , respectively) and lower than the estimated mean in session 3 (Pearson residual - 3.133). Movement synchrony was higher than the estimated mean in session 10 (Pearson residual 6.012) and lower than the estimated mean in sessions 2 and 6 (Pearson residual -4.004 and -3.282 , respectively). In sessions 2 and 6 , the participants wore autonomic nervous system measurement equipment that restricted the movement of their non-dominant hand. In the sessions in which the baby sat on one of the parents' laps (sessions 3, 6,7 , and 10), the amount of synchrony did not differ from other sessions (except for posture synchrony in session 3 , and movement synchrony in session 6). In the other sessions, no posture or movement synchrony frequency was higher or lower than the estimated means.

\section{Qualitative Analysis of the Therapy Process}

The qualitative analysis of the therapy process began with an inspection of the frequencies of posture and movement synchronies in the sessions (Figs. 1 and 2) and the participants' evaluations of the therapeutic alliance in the sessions (Fig. 3). After this, the nonverbal synchronies were contrasted with the evaluations of the alliance.

\section{Nonverbal Synchrony}

Posture synchrony (Fig. 1) occurred mainly in dyads, and only rarely between three persons. Three dyads had more posture synchrony than any of the others: the co-therapists (all sessions except 3 and 6), the male client (B) and therapist 1 (all sessions except 6), and the female client (A) and therapist 2 (from session 4 through session 9). Therapist 2 was also in synchrony with the male client in most of the sessions (except for session 6). It seemed that therapist 2 was more involved in posture synchrony than therapist 1 . At the beginning of the therapy, the female client was not in posture synchrony with anyone but her husband. As the therapy progressed, she became more actively involved in the nonverbal synchronies, and she and therapist 2 were in posture synchrony quite often. Posture synchrony between the clients was not that frequent, but occurred in sessions 2, 3, 5, 8, 9, and 10 .

Movement synchronies per synchrony group in the sessions are shown in Fig. 2. The movement synchronies presented are the sum of all the movement synchrony types, i.e., head, arm, hand, leg, torso, and other. A large portion of the movement synchronies in general were head movement 
Fig. 1 Posture synchrony per synchrony group per session. This figure shows the posture synchronies per synchrony group for every session observed (2-9)

Fig. 2 Movement synchrony frequencies per synchrony group per session. This figure shows the sum of all movement synchronies per synchrony group for every session observed (2-9)

Fig. 3 The participants' SRS scores per session. This figure shows the participants' evaluations of the alliance in each session (1-9) evaluated with the Session Rating Scale (SRS). The sum of scores is presented for each participant for every session. For clarity of the figure, the $y$-axis starts from the score 25 and not 0

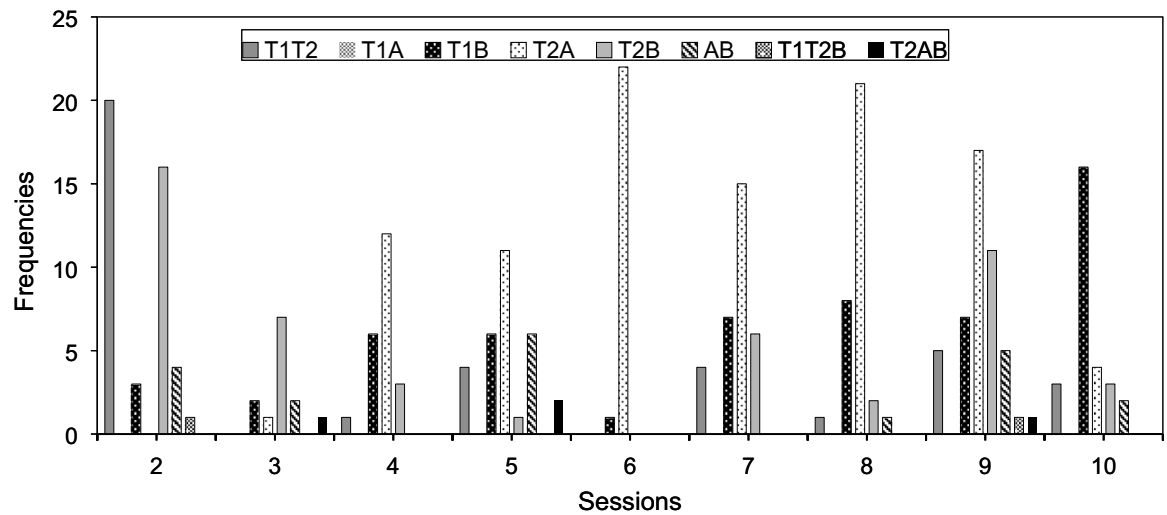

Movement synchrony frequencies per synchrony group per session

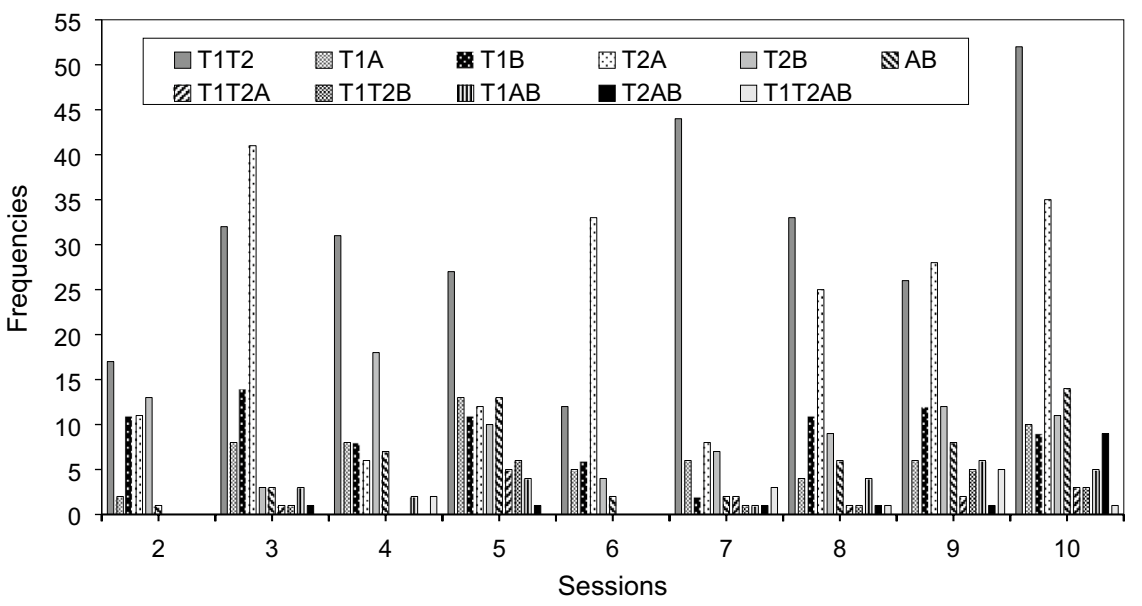

The participants' SRS scores per session

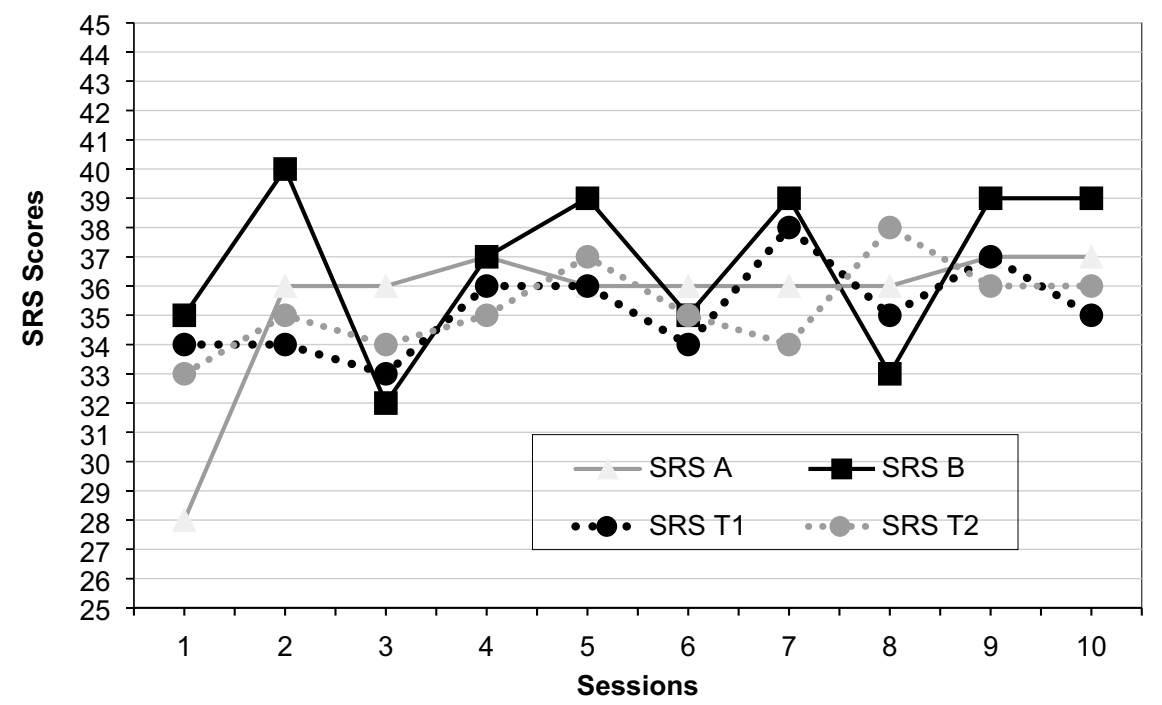


synchronies, i.e., nodding. Through the therapy process, there was movement synchrony in dyads, triads, and even the tetrad. Movement synchrony in general, as well as triadic and tetradic synchronies, occurred with greater frequency toward the end of the therapy process (sessions 8, 9, and 10). Session 6 differed from all other sessions regarding the amount of posture and movement synchrony in that it had the least amount of synchrony. The co-therapists and therapist 2 and the female client showed the largest amount of movement synchrony throughout the therapy process.

\section{The Therapeutic Alliance}

The alliance scores (SRS) evaluated by the therapists and the clients varied across sessions. Figure 3 shows the sum of the SRS scores for each participant per session. The first session is included in the figure even though it was not available for nonverbal synchrony analysis. The first session was evaluated by all participants to have a weak alliance; the female client in particular evaluated the alliance to be extremely weak.

When we examined the overall process, it seemed that the alliance improved from sessions 2 to 5 ; however, the alliance was evaluated to be weaker in session 6 . After session 6 , the participants' evaluations diverged. The female client's evaluations were stable from session 2 onward, showing only a slight improvement during the last two sessions, while the male client's evaluations changed from session to session. The therapists seemed to agree on the alliance from sessions 1 to 6 , after which their evaluations differed; that is, when one therapist evaluated the alliance to be stronger than in the preceding session, the other therapist evaluated it to be weaker. The male client's and therapist 1's alliance evaluations were remarkably similar from session 3 onward and differed only in the last session.

\section{Triangulation of Nonverbal Synchronies and Evaluations of the Therapeutic Alliance}

At the beginning of the therapy process, the therapists evaluated the alliance to be weak (sessions 1 to 3 ). In the second session, the co-therapists frequently had posture synchrony, and in the third session, they had more movement synchrony than in the previous session. One interpretation of this could be that the therapists worked at the embodied level, i.e., nonverbally to establish a secure base for the therapy. The sixth session was also evaluated by all participants to have a weaker alliance; it is noteworthy that there was no posture synchrony between the therapists in this session, and movement synchrony between the co-therapists was not as frequent as in other sessions. The posture synchrony in the sixth session was almost entirely between therapist 2 and the female client. This dyad was also responsible for the greatest share of movement synchrony in the same session.
It is interesting to note that when the sessions had been evaluated to have a weaker alliance (session 1 by all participants and session 6 by all except the female client), the cotherapists synchronized to each other more in the subsequent session. It is as if they were making a joint embodied effort to strengthen the alliance by creating a rapport between themselves, thereby possibly communicating to the clients that they were interested in what was under discussion. The female client, who was involved in most of the synchronies in session 6, did not evaluate the alliance to be weaker in that session. But all in all, the female client evaluated all the sessions in such a stable way that it was difficult to interpret her nonverbal synchrony patterns and her evaluations. ${ }^{2}$

When the individual evaluations of the alliance and the nonverbal synchronies were compared, it was found that the male client evaluated the alliance to be stronger in sessions $2,5,7,9$, and 10 , where there was posture synchrony between the co-therapists. ${ }^{3}$ In the fourth session, the female client evaluated the alliance to be slightly stronger; in this session, she began to have more posture synchrony mainly with therapist 2 . Before this session, she had mainly been in posture synchrony with her husband.

In the sessions in which the male client and therapist 1 evaluated the alliance to be weaker, the female client was in movement synchrony with therapist 2 (sessions 3, 6, and 8). In these sessions, these movement synchronies were mainly head nods, while the female client talked actively and therapist 2 responded.

In the sessions in which the co-therapists evaluated in opposite directions (sessions 7, 8, 9, and 10), there were no clear patterns to discern from the nonverbal synchronies. Toward the end of the therapy, both movement and posture synchronies were more frequent and involved more participants; at the same time, the participants evaluated the alliance to be stronger.

\section{An Episode from a Session Illustrating Posture Synchrony}

The following passage is a short episode from the second therapy session, showing how posture synchrony occurred during the dialogue. Before this episode, there had been

\footnotetext{
${ }^{2}$ Nonparametric Spearman's rank-order correlations with bootstrapped confidence intervals were calculated to analyze the relationship between the alliance in the sessions and the observed behaviors. For readability, only the nonverbal synchrony groups and SRS scores with significant correlations are included in the tables in "Appendix 2". There were no significant correlations between the female client's SRS evaluations and the nonverbal synchrony patterns.

3 This relationship was confirmed with the correlational analysis of the frequencies of nonverbal synchrony and the male client's evaluations of the therapeutic alliance, which can be seen in Table 7 in "Appendix 2".
} 
a discussion about an argument the couple had had. The female client had felt that the male client had not been loyal to her and their family. Rather, she felt he had been loyal to his family of origin, as he did not defend her against the criticism his family directed at her. Just before this episode, therapist 1 had challenged the male client by questioning whether he felt he would be abandoned by his family of origin if he took his wife's side, and he admitted it would be difficult at first. Posture synchrony is marked with italics in the transcript below the spoken dialogue, with brackets indicating the exact time at which it occurred. Transcript notations are explained in "Appendix 3". The pseudonyms "John" and "Lisa" are used for the couple. Therapist 1 is T1 and therapist 2 is $\mathrm{T} 2 .^{4}$

\section{((T2 is in the same posture as John))}

T2: yes

T1: but is it possibly (1) somehow what you think (.) Lisa that (.).hh that if: and apparently when John has had continuous experiences about that family (.) not holding on to him (1) sort of abandoning in different ways (.) different family members there (.) there happen things that are not spoken of et cetera it is very

[((T2 leaves the shared posture with John $))$

(1).hh sort of uncertain (.).hh that precisely this (.) uncertainty (.) draws ((gestures)) to that direction

Lisa: $\quad \mathrm{mmm} \mathrm{I-}$

\section{[((T2 takes the same posture as John $))$}

T1: that th-that somehow one would have to like see if there still is something (.) that one can hold on to and then when: (.) are you (.) I mean this is so silly but (.) people do

Lisa: $\mathrm{mm}$

T1: and feel silly things (.) that when there is you (.) who is there (.) kids who are

[((T2 leaves the shared posture $))$

there (.) so (.) so it is like (.) quotation marks self-evident

[((T2 takes John's posture $))$

Lisa: $\mathrm{mmm}$ ? ((looks up))

T1: $\quad \mathrm{i}$-is it possible that it goes something like this

Lisa: yea

T1: illogically but (.) in some way in its illogicality (.) understandable

[((John leaves the shared posture with T2))

Lisa: $\quad$ mmm (1) I did somehow think that it in a way comes from there (1) like from that kind of (.) longing for a family or (.) like longing for love from that family or something (1)

T2: ((deep sigh, clears throat)) [((both therapists shift their postures $))$

\footnotetext{
$\overline{4}$ The transcript was translated by one of the therapists.
}

In this episode, therapist 2 moved to and from posture synchrony with the male client. This could be interpreted as therapist 2 showing empathy toward the male client when therapist 1 was talking about his actions and trying to make sense of them together with the female client. The setting with two therapists present made it possible for one therapist to speak of difficult topics, while the other therapist could empathize with the other client at the physical level. Interestingly, when therapist 1 was about to finish his turn speaking, the male client left the shared posture with therapist 2 , as if he were communicating to others that he was fine with the therapist's comment. Therapist 2 moved a great deal in this episode, which could also be interpreted as him being uneasy about what stand he should take in the situation. After this episode, they continued talking about the violence that had occurred between the couple and the impact it had had on the trust between the couple.

\section{Discussion}

The aim of this study was to create a coding scheme for observing nonverbal synchrony in couple therapy, focusing on implicit imitations of identical nonverbal behaviors in a temporally precise recording of behaviors. Observation was chosen as the method, since frame-differencing methods would be unable to discern the similarity of movements, even though observation is time-consuming and reliant on the expertise of the observers. The qualitative analysis resulted in two main categories: posture synchrony and movement synchrony (mimicry). Posture synchrony has been shown to be related to rapport (Sharpley et al. 2001) and perceived empathy of the therapists (Maurer and Tindall 1983), and movement synchrony (i.e., mimicry) has been shown to increase liking and rapport (Chartrand and Lakin 2013) and to be related to empathy (Sonnby-Borgström and Jönsson 2003). Our interest was to see whether these nonverbal synchrony behaviors, which have been shown to have an impact on relationships, also affected the participants' evaluations of the therapeutic alliance in couple therapy.

Since the coding scheme was developed based on earlier research results, it is a theoretically informed method for studying nonverbal synchrony in psychotherapy. Theoretical models by Baimel et al. (2015) and Koole and Tschacher (2016) have suggested that nonverbal synchrony aids in understanding others; however, this topic requires additional research, especially in the context of couple therapy.

Temporal precision was important because an additional aim was to use the coding scheme with information from other modalities in psychotherapy, such as dialogue. In fact, the coding scheme has already been used in relation to dialogue and the embodied reactions of participants in two qualitative studies (Kykyri et al. 2019; Nyman-Salonen et al. 2020). 
When the coding scheme is used in qualitative research, it is very informative to the researcher who observes the sessions. Even watching sessions without listening to the dialogue gives the observer insight into the session's atmosphere. When using automated methods, this tacit information is absent.

Creating a coding scheme was not a simple task. It was vital that the definitions of the observed categories be unambiguous in order for the observers to make similar observations. Excellent interrater reliability was obtained for the coding scheme. This was partly due to the concrete definitions of the categories of nonverbal synchrony, based on the exact physical appearance of the nonverbal behaviors of the participants. This reduced the observational bias as it required less subjective evaluation.

During the development, one couple therapy process was observed. The couple had come to therapy because of loyalty issues in the relationship, and there was a history of interpersonal violence between the couple. The case was chosen from a data set gathered in the Relational Mind research project. The data set comprised couple therapy cases with two therapists present at each session; the participants' autonomous nervous system reactions were recorded in some of the sessions. For the couple therapy case studied here, there was less movement synchrony in the sessions in which the participants wore autonomic nervous system equipment, which restricted the movements of the non-dominant hand. This indicates that even though the research setting was designed to be as natural as possible, the measurement equipment did restrict the participants' movements and influenced the sessions' nonverbal movement patterns. The amount of nonverbal synchrony differed between sessions and between the dyads involved. No overall clear-cut patterns could be discerned, except that movement synchrony was more prevalent toward the end of the therapy process, and all participants were involved.

Couple therapy as a context makes studying nonverbal synchrony intriguing, since there are multiple relationships present, namely, the relationship between the spouses and the relationship between the therapist(s) and each of the spouses separately. Nonverbal synchrony between the couple can signal how satisfied the clients are with their relationship (Julien et al. 2000), whereas synchrony between therapist and client can signal empathy (Maurer and Tindall 1983) or rapport (Sharpley et al. 2001). The synchrony between the couple in the case studied here was not very considerable; this was expected, since they had difficulties in their relationship. As there were two therapists present, this resulted in four possible therapy-client dyads that could synchronize. Different therapist-client dyads synchronized in different sessions. Nonverbal synchrony could be observed both between those who participated in the conversation and between the listeners. This has previously been demonstrated in a microanalytic case study on alliance formations in couple therapy (Kykyri et al. 2019). With two therapists present, nonverbal synchrony between the co-therapists also occurred. Nonverbal synchrony between the co-therapists might be interpreted as a sign of the therapists being in rapport or supporting each other during the task at hand.

In this couple therapy case, both therapists synchronized their postures to that of the male client. It might be that both therapists implicitly ${ }^{5}$ recognized the importance of connecting with the male client because of his history of interpersonal difficulties, including violence. According to recent studies, patients with whom therapists synchronize more tend to report more interpersonal problems (Ramseyer 2020). This is well in line with the case studied here. A high amount of nonverbal synchrony between therapist and client has also been related to non-improvement of the client (Paulick et al. 2018). It has been suggested that therapists make an increased effort with these patients. This might also be true for the case studied here. However, previous research on nonverbal synchrony in psychotherapy has been conducted in individual psychotherapy settings, which makes it difficult to draw conclusions from them in the context of couple therapy. One aspect that might also influence nonverbal synchrony was that both therapists were male. It could have been that it was easier for them to implicitly synchronize with the male client.

In this case, the other therapist also implicitly synchronized to the female client, possibly with the aim of keeping her involved in the therapy process and encouraging her to talk about her feelings and thoughts concerning the relationship. Importantly, it seemed that the therapists counterbalanced the nonverbal synchronies and took care that both spouses were involved in nonverbal synchrony with the therapists. This could be an implicit, nonverbal means of preventing the development of a split alliance, in which one spouse feels therapy is beneficial but the other does not.

The presence of two therapists in the case study made it possible to investigate how they managed the therapeutic process at the embodied level. The co-therapists synchronized to each other's postures, especially at the beginning of the therapy process, and movement synchrony between the therapists (mainly in the form of head nods) was frequent throughout the therapy process. In addition, the two therapists seemed to implicitly take on different positions during the sessions. On the level of the therapy process as a whole, one therapist worked more at the bodily level, synchronizing to the other participants, while the other therapist remained more passive in his bodily behavior. However, the positions of the therapists could also alter rapidly during sessions, so that the more passive therapist engaged actively in nonverbal synchrony, as the other therapist was less active. The patterns were dependent on the division of tasks between the

\footnotetext{
5 Since the therapy was talk therapy and emphasized dialogical methods, no bodily based interventions were used deliberately.
} 
therapists, the topics discussed, and the participants involved in the discussion.

In this case study, the episode chosen to illustrate posture synchrony showed the division of tasks between the therapists. While one therapist talked about the male client, trying to make sense of his motivations together with the female client, the other therapist synchronized his postures to the male client, thus empathizing with him, as the male client might have felt threatened by being under scrutiny.

In this case study, the sixth session stands out in the investigation of the therapy process. There was less nonverbal synchrony observed between all participants, and almost all synchronies observed were between the female client and one of the therapists. The possibility cannot be ruled out that the autonomic nervous system equipment that the participants wore had an impact on the amount of movement synchrony. However, previous research on this particular session has shown that the female client brought up the threat of divorce (Itävuori et al. 2015). It seems likely that discussing difficult topics had an impact on the nonverbal synchronies: when the female client brought up this difficult subject, one of the therapists responded to it, signaling with his synchrony that he was interested in hearing what she had to say, while the other participants did not react to it by synchronizing nonverbally. This session was evaluated by all participants except the female client to have a weaker alliance than the previous session.

As for the relationship between nonverbal synchrony and the alliance, results of the qualitative analysis were mixed: being involved in nonverbal synchrony was not always related to one evaluating the alliance to be stronger, and watching others being in synchrony sometimes resulted in the observer rating the alliance to be weaker and sometimes stronger.

The female client evaluated the alliance in the sixth session to be of the same strength as the other sessions (when the others evaluated the alliance to be weaker). As previously mentioned, she actively engaged in both posture and movement synchrony in the session with one of the therapists; in fact, most of the nonverbal synchronies in that session occurred between the female client and one of the therapists. The fact that most of the synchronies in that session occurred in only one dyad could be seen as a split in nonverbal synchrony behavior. Interestingly, everyone except the female client evaluated the session to be weaker in alliance, even the therapist who was involved in nonverbal synchrony with her. However, as a precaution, it must be said that the female client's evaluations of the alliance remained quite stable throughout the therapy process, while the male client's evaluations of the alliance changed from session to session.

An opposing example of how watching others synchronize affected the evaluations of the alliance was that in the sessions in which the co-therapists were frequently in posture synchrony, the male client evaluated the alliance to be stronger. Posture synchrony between the co-therapists could have been seen as a sign of rapport between the cotherapists; alternatively, it could have created a general impression of empathy, which might have affected the male client. Observing nonverbal synchrony can thus have opposing effects, depending on the context and how the observer interprets the nonverbal synchrony; that is, it can be seen as something positive, like an empathic stance, or it can leave the observer feeling like an outsider.

One consideration when interpreting the alliance measures is that the clients evaluated the co-therapists as a team and the therapists evaluated the alliance in relation to both spouses simultaneously; therefore, it was not possible to see whether there would have been differences in alliance related to one of the spouses or one of the therapists. Further research is needed with a more specific alliance measure to evaluate the alliance for each relationship separately, as split alliances have been associated with dropping out of therapy (e.g., Muñiz de la Peña et al. 2009). It would be interesting to see how the dyadic nonverbal synchrony patterns affect the evaluations of alliance if one is involved in the synchrony or merely observing it.

One interesting result was that there seemed to be a peak in synchrony between the co-therapists in the session following a session that was evaluated to have weaker alliance. Earlier research has shown that there can be a high amount of nonverbal synchrony between the therapist and nonimproving patients, possibly indicating therapists making an increased effort with these patients (Paulick et al. 2018). Here, it seemed that the therapists' implicit and joint embodied work (nonverbal synchrony) increased as the alliance had been weaker in the previous session. It might be that this played an important role in facilitating the therapy process and fostering the alliance.

In this therapy process, movement synchrony increased toward the end of the therapy process; at the same time, the participants' evaluations of the alliance improved. Movement synchrony could be seen as an indication that all participants were actively involved in the therapy process, and this was reflected in the alliance.

When evaluating the results, it must be remembered that the therapy conducted was talk therapy, emphasizing words and dialogue, and no deliberate bodily interventions were used. The research data was selected for analysis from a dataset of sessions of a research project that studied synchrony of autonomous nervous system reactions. The therapists were aware of this research aim, but not aware that their overt bodily behavior, especially nonverbal synchrony, would be analyzed. All synchronies were implicit and were not used as interventions. 


\section{Clinical Implications}

One must be cautious when suggesting clinical implications based on this research, since it is only one case study and the results were mixed. However, the coding scheme could be used by couple therapists in supervision or in couple therapy training, as one important aspect is for the couple therapist to become aware of the nonverbal synchrony patterns in the sessions. ${ }^{6}$ Videotaping could be beneficial since it might not always be possible to notice nonverbal synchrony patterns during the sessions. As it is not common practice to have two therapists present, the individual therapists conducting couple therapy should be aware of their nonverbal interactions with each spouse. It might be that one is more inclined to be in nonverbal synchrony with one of the spouses, which could potentially contribute to a nonverbal split.

We assume that nonverbal synchrony is probably best as it happens implicitly and not deliberately. Nonverbal behavior affects the atmosphere of the session, and it can easily be interpreted negatively if a client feels it is used on purpose. However, when the therapist's general awareness of nonverbal behavior is better, then it is possible to remain nonverbally receptive to one spouse while talking to the other spouse.

\section{Limitations}

Limitations concerning this study are as follows: (1) the coding scheme requires trained raters, and it is time-consuming. Unfortunately, no automated method for depicting static posture synchrony and movement synchrony of similar movements (mimicry) was found that could be used in sessions as lengthy as those in this case study were, and that would be secure enough to use with authentic psychotherapy cases. In the future, the coding scheme could be used to create computerized and partly automatic solutions for detecting implicit imitation of postures and movements. It would also be interesting to compare the nonverbal synchrony obtained by the coding scheme to nonverbal synchrony scores obtained by frame-differencing methods to see in detail how they differ in their definition of nonverbal synchrony. (2) The developmental process of the coding scheme began with the detailed observation of one couple therapy process. This idiographic stance could be seen as a disadvantage since it might only show nonverbal synchrony representative of this specific case, and it is not possible to make any generalizations about nonverbal synchrony in couple therapy. However, idiographic research (Ramseyer 2020) on individual psychotherapy and the couple therapy

\footnotetext{
${ }^{6}$ One could first concentrate on recognizing only posture synchronies, which has been related to empathy (Maurer and Tindall 1983) and been found in important parts of the therapy session (Raingruber 2001); later, one could move on to observing movement synchrony. The manual for the coding scheme is available from the first author.
}

case study presented here have shown that the relationship between nonverbal synchrony and alliance is more complex than earlier nomothetic research has shown. In the future, analysis with more couple therapy cases and a larger dataset is needed to test for the generalizability of the findings. (3) The omission of the first therapy session could be seen as a limitation. This was due to a technical problem with the recording, showing only the couple and not the therapists on the video. This was unfortunate, since the first session is usually very important in creating the alliance. (4) In some sessions, there was a baby present, which could influence the observational process. However, in the sessions in which the baby was on either of the parents' laps, there was not a considerable difference in the amount of posture or movement synchrony from the sessions in which this did not happen. The high interrater reliability also worked against this interpretation since it showed that the presence of the baby did not influence the observational process. Thus, this was a beneficial aspect in using observers rather than an automated frame-differencing method; it would not have been possible to use the videos with such a method because the baby on the lap would penetrate the regions of interest, resulting in erroneous data. (5) One limitation for generalizability could be the use of two therapists. This is, however, the way couple therapy is always conducted at the Psychotherapy Training and Research Centre at the University of Jyväskylä. One motivation for the use of two therapists is that it inhibits split alliances. In this case, the co-therapists were both male, and it might be that the results would have been different if the co-therapists had been of different sexes. (6) If the frequencies of nonverbal synchrony obtained with the coding scheme were used for quantitative research alone, it would be necessary to include a pseudosynchrony condition. Pseudosynchrony refers to creating a shuffled data set against which the real nonverbal synchronies are compared. This helps to establish whether nonverbal synchrony occurs above the level of chance; without the pseudosynchrony condition, it is not possible to establish this. The reason for the exclusion of pseudosynchrony was mainly the small amount of data in this case study; it prevented the shuffling of data points in order to create a surrogate dataset, according to the procedure presented by Louwerse et al. (2012). In addition, the subject structure of synchrony groupings limited the options for statistical analysis. Further research with a larger data set is required to enable pseudosynchrony calculations.

Studying the psychotherapeutic process by observing nonverbal behavior from videos of couple therapy can be a daunting task. For the researcher wishing to undertake a similar research process, we find it important that the phenomenon studied should be either well established in earlier research, or something that couple therapists emphasize based on their clinical experience. Choosing observation as the research method makes it vital to have a good team 
working together, since the replicability of the observations is crucial for making the research scientifically valid.

\section{Conclusion}

In conclusion, it is clear that research on nonverbal synchrony in couple therapy is an understudied area, as this study is one of the first on the subject. The coding system created here is replicable in other therapy settings. It can be used when there are features in videos that prevent the use of automated frame-differencing methods (such as lightning issues or disturbing factors present in the video). It could also be used in supervision or psychotherapy training to enhance therapists' awareness of their nonverbal behavior.

This case study showed that couple therapy is a complex system that enables many constellations of nonverbal synchrony between the participants. Usually, nonverbal synchrony occurs in dyads, but as there were four participants present in the couple therapy case studied here, even triadic and tetradic synchrony was possible, something that current methods have not yet been able to study.

In couple therapy, nonverbal synchrony affected not only the participants who were involved in it but also participants who were not involved in it. This suggests that the relationship between nonverbal synchrony and alliance in couple therapy is more complex than earlier research on individual psychotherapy has shown.

In general, more research on nonverbal synchrony in couple therapy is important from both an idiographic and a nomothetic stance, since the study presented here suggests that nonverbal synchrony affects the relationship between therapist and patient; the relationship is an important aspect of the therapeutic alliance that can influence the outcome of therapy.

Acknowledgements I thank my supervisors Professor Juha Holma and Professor Wolfgang Tschacher for their valuable comments on the manuscript, and Joona Muotka for statistical assistance. The research project Relational mind in events of change in multiactor therapeutic dialogues was funded by the Academy of Finland (Human Mind Research Program 2013-2016) under Grant Number 265492 (including the design of the research project and the gathering of the data). The development of the method presented here was funded by the Department of Psychology at the University of Jyväskylä in Finland; the finalizing of the manuscript was funded by the Kone Foundation.

Funding Open access funding provided by University of Jyväskylä (JYU).

Open Access This article is licensed under a Creative Commons Attribution 4.0 International License, which permits use, sharing, adaptation, distribution and reproduction in any medium or format, as long as you give appropriate credit to the original author(s) and the source, provide a link to the Creative Commons licence, and indicate if changes were made. The images or other third party material in this article are included in the article's Creative Commons licence, unless indicated otherwise in a credit line to the material. If material is not included in the article's Creative Commons licence and your intended use is not permitted by statutory regulation or exceeds the permitted use, you will need to obtain permission directly from the copyright holder. To view a copy of this licence, visit http://creativecommons.org/licenses/by/4.0/.

\section{Appendix 1}

\section{Frequencies of Posture and Movement Synchrony Per Session Per Synchrony Group}

See Tables 5 and 6.
Table 5 Posture synchronies per session per synchrony group

\begin{tabular}{lrrrrrrrrr}
\hline Session & 2 & 3 & 4 & 5 & 6 & 7 & 8 & 9 & 10 \\
T1T2 & 20 & 0 & 1 & 4 & 0 & 4 & 1 & 5 & 3 \\
T1A & 0 & 0 & 0 & 0 & 0 & 0 & 0 & 0 & 0 \\
T1B & 3 & 2 & 6 & 6 & 1 & 7 & 8 & 7 & 16 \\
T2A & 0 & 1 & 12 & 11 & 22 & 15 & 21 & 17 & 4 \\
T2B & 16 & 7 & 3 & 1 & 0 & 6 & 2 & 11 & 3 \\
AB & 4 & 2 & 0 & 6 & 0 & 0 & 1 & 5 & 2 \\
T1T2A & 0 & 0 & 0 & 0 & 0 & 0 & 0 & 0 & 0 \\
T1T2B & 1 & 0 & 0 & 0 & 0 & 0 & 0 & 1 & 0 \\
T1AB & 0 & 0 & 0 & 0 & 0 & 0 & 0 & 0 & 0 \\
T2AB & 0 & 1 & 0 & 2 & 0 & 0 & 0 & 1 & 0 \\
T1T2AB & 0 & 0 & 0 & 0 & 0 & 0 & 0 & 0 & 0 \\
Sum dyadic & 43 & 12 & 22 & 28 & 23 & 32 & 33 & 45 & 28 \\
Sum triadic & 1 & 1 & 0 & 2 & 0 & 0 & 0 & 2 & 0 \\
Sum tetradic & 0 & 0 & 0 & 0 & 0 & 0 & 0 & 0 & 0 \\
Sum post & 44 & 13 & 22 & 30 & 23 & 32 & 33 & 47 & 28 \\
\hline
\end{tabular}

Sessions 2-9. Dyads therapist 1 and therapist 2, therapist 1 and client A, therapist 1 and client B, therapist 2 and client A, therapist 2 and client B, and the clients A and B. Triads co-therapists and client A, co-therapists and client B, therapist 1 and the spouses, therapist 2 and the spouses. Tetrad all participants 
Table 6 Movement synchronies per session per synchrony group

\begin{tabular}{lrrrrrrrrr}
\hline Session & 2 & 3 & 4 & 5 & 6 & 7 & 8 & 9 & 10 \\
T1T2 & 17 & 32 & 31 & 27 & 12 & 44 & 33 & 26 & 52 \\
T1A & 2 & 8 & 8 & 13 & 5 & 6 & 4 & 6 & 10 \\
T1B & 11 & 14 & 8 & 11 & 6 & 2 & 11 & 12 & 9 \\
T2A & 11 & 41 & 6 & 12 & 33 & 8 & 25 & 28 & 35 \\
T2B & 13 & 3 & 18 & 10 & 4 & 7 & 9 & 12 & 11 \\
AB & 1 & 3 & 7 & 13 & 2 & 2 & 6 & 8 & 14 \\
T1T2A & 0 & 1 & 0 & 5 & 0 & 2 & 1 & 2 & 3 \\
T1T2B & 0 & 1 & 0 & 6 & 0 & 1 & 1 & 5 & 3 \\
T1AB & 0 & 3 & 2 & 4 & 0 & 1 & 4 & 6 & 5 \\
T2AB & 0 & 1 & 0 & 1 & 0 & 1 & 1 & 1 & 9 \\
T1T2AB & 0 & 0 & 2 & 0 & 0 & 3 & 1 & 5 & 1 \\
Sum dyadic & 55 & 101 & 78 & 86 & 62 & 69 & 88 & 92 & 131 \\
Sum triadic & 0 & 6 & 2 & 16 & 0 & 5 & 7 & 14 & 20 \\
Sum tetradic & 0 & 0 & 2 & 0 & 0 & 3 & 1 & 5 & 1 \\
Sum & 55 & 107 & 82 & 102 & 62 & 77 & 96 & 111 & 152 \\
\hline
\end{tabular}

Sessions 2-9. Dyads therapist 1 and therapist 2, therapist 1 and client A, therapist 1 and client B, therapist 2 and client A, therapist 2 and client B, and the clients A and B. Triads co-therapists and client A, co-therapists and client B, therapist 1 and the spouses, therapist 2 and the spouses. Tetrad all participants

\section{Appendix 2}

\section{Nonparametric Spearman's Rank-Order \\ Correlations with Bootstrapped Confidence \\ Intervals for Calculating the Relationship Between \\ the Alliance in the Sessions and the Observed \\ Nonverbal Synchronies}

See Tables 7, 8 and 9.

Table 7 Correlations of the male client B's SRS scores to the nonverbal posture and movement synchrony groups

\begin{tabular}{|c|c|c|c|c|}
\hline & $\begin{array}{l}\text { Co-therapists' posture } \\
\text { synchrony }\end{array}$ & $\begin{array}{l}\text { T2 and client A move- } \\
\text { ment synchrony }\end{array}$ & $\begin{array}{l}\text { T2 and client B move- } \\
\text { ment synchrony }\end{array}$ & $\begin{array}{l}\mathrm{T} 1, \mathrm{~T} 2 \text {, and client } \mathrm{A} \\
\text { movement syn- } \\
\text { chrony }\end{array}$ \\
\hline Client B SRS relationship & $\begin{array}{l}0.71 * \\
{[0.18,0.95]}\end{array}$ & $\begin{array}{l}-0.58 \\
{[-0.96,0.25]}\end{array}$ & $\begin{array}{l}0.33 \\
{[-0.32,0.84]}\end{array}$ & $\begin{array}{l}0.22 \\
{[-0.56,0.77]}\end{array}$ \\
\hline Client B SRS goals and topics & $\begin{array}{l}0.84 * * \\
{[0.56,0.92]}\end{array}$ & $\begin{array}{l}-0.28 \\
{[-0.88,0.59]}\end{array}$ & $\begin{array}{l}0.44 \\
{[-0.29,0.88]}\end{array}$ & $\begin{array}{l}0.50 \\
{[-0.97,0.98]}\end{array}$ \\
\hline $\begin{array}{l}\text { Client B SRS } \\
\text { approach and method }\end{array}$ & $\begin{array}{l}0.89 * * \\
{[0.6,0.97]}\end{array}$ & $\begin{array}{l}-0.30 \\
{[-0.93,0.65]}\end{array}$ & $\begin{array}{l}0.45 \\
{[-0.46,0.95]}\end{array}$ & $\begin{array}{l}0.55 \\
{[-0.71,0.95]}\end{array}$ \\
\hline Client B SRS overall & $\begin{array}{l}0.68^{*} \\
{[0.00,0.99]}\end{array}$ & $\begin{array}{l}-0.37 \\
{[-0.91,0.33]}\end{array}$ & $\begin{array}{l}0.89 * * \\
{[0.73,0.95]}\end{array}$ & $\begin{array}{l}0.10 \\
{[-0.55,0.81]}\end{array}$ \\
\hline Client B SRS sum of subscales & $\begin{array}{l}0.92 * * \\
{[0.71,0.99]}\end{array}$ & $\begin{array}{l}-0.42 \\
{[-0.93,0.56]}\end{array}$ & $\begin{array}{l}0.60 \\
{[-0.12,0.97]}\end{array}$ & $\begin{array}{l}0.28 \\
{[-0.58,0.86]}\end{array}$ \\
\hline
\end{tabular}

Values in brackets indicate a 95\% confidence interval for each correlation. For readability, only the nonverbal synchrony behavior groups and/or individual scores for SRS, including significant correlations, are presented

*Indicates $p<0.05$

**Indicates $p<0.01$ 
Table 8 Correlations of therapist 1's SRS scores to the nonverbal posture and movement synchrony groups

\begin{tabular}{llllll}
\hline & $\begin{array}{l}\text { Co-therapists' } \\
\text { posture syn- } \\
\text { chrony }\end{array}$ & $\begin{array}{l}\text { Therapist } 1 \text { and client } \\
\text { B posture synchrony }\end{array}$ & $\begin{array}{l}\text { Co-therapists' } \\
\text { movement syn- } \\
\text { chrony }\end{array}$ & $\begin{array}{l}\text { T2 and client B } \\
\text { movement syn- } \\
\text { chrony }\end{array}$ & $\begin{array}{l}\text { T2, client A, and client } \\
\text { B movement synchrony }\end{array}$ \\
\hline T1 SRS relationship & $0.78^{*}$ & $0.69^{*}$ & 0.10 & $0.70^{*}$ & 0.26 \\
& {$[0.43,0.97]$} & {$[-0.21,0.96]$} & {$[-0.72,0.74]$} & {$[0.00,0.95]$} & {$[-0.21,0.66]$} \\
T1 SRS goals and topics & -0.13 & $-0.84^{*}$ & $-0.76^{*}$ & -0.21 & $-0.68^{*}$ \\
& {$[-0.73,0.81]$} & {$[-0.96,-0.56]$} & {$[-0.97,-0.18]$} & {$[-0.75,0.65]$} & {$[-0.95,-0.29]$} \\
T1 SRS approach and method & 0.31 & $0.76^{*}$ & 0.62 & 0.19 & 0.48 \\
T1 SRS overall & {$[-0.77,0.98]$} & {$[0.30,0.91]$} & {$[0.00,0.92]$} & {$[-0.86,0.89]$} & {$[-0.12,0.85]$} \\
& 0.31 & $0.76^{*}$ & 0.62 & 0.19 & 0.48 \\
{$[-0.77,0.98]$} & {$[0.30,0.91]$} & {$[0.00,0.92]$} & {$[-0.86,0.89]$} & {$[-0.12,0.85]$} \\
\hline
\end{tabular}

Values in brackets indicate a 95\% confidence interval for each correlation. For readability, only the nonverbal synchrony behavior groups and/or individual scores for SRS, including significant correlations, are presented

*Indicates $p<0.05$

$* *$ Indicates $p<0.01$

Table 9 Correlations of therapist 2's SRS scores to the nonverbal posture and movement synchrony groups

\begin{tabular}{|c|c|c|c|c|}
\hline & $\begin{array}{l}\text { Co-therapists' posture } \\
\text { synchrony }\end{array}$ & $\begin{array}{l}\text { Therapist } 1 \text { and client B } \\
\text { posture synchrony }\end{array}$ & $\begin{array}{l}\text { Client A and B posture } \\
\text { synchrony }\end{array}$ & $\begin{array}{l}\mathrm{T} 1, \mathrm{~T} 2 \text {, and client } \mathrm{A} \\
\text { movement syn- } \\
\text { chrony }\end{array}$ \\
\hline T2 SRS relationship & $\begin{array}{l}-0.16 \\
{[-0.90,0.63]}\end{array}$ & $\begin{array}{l}0.73^{*} \\
{[0.56,0.98]}\end{array}$ & $\begin{array}{l}-0.05 \\
{[-0.56,0.55]}\end{array}$ & $\begin{array}{l}0.27 \\
{[-0.46,0.93]}\end{array}$ \\
\hline T2 SRS goals and topics & $\begin{array}{l}-0.70^{*} \\
{[-0.9,-0.25]}\end{array}$ & $\begin{array}{l}-0.43 \\
{[-0.81,0.08]}\end{array}$ & $\begin{array}{l}-0.08 \\
{[-0.89,0.65]}\end{array}$ & $\begin{array}{l}-0.29 \\
{[-0.84,0.34]}\end{array}$ \\
\hline T2 SRS approach and method & $\begin{array}{l}0.47 \\
{[-0.74,0.93]}\end{array}$ & $\begin{array}{l}0.83 * * \\
{[0.58,0.93]}\end{array}$ & $\begin{array}{l}0.25 \\
{[-0.43,0.83]}\end{array}$ & $\begin{array}{l}0.75^{*} \\
{[0.29,0.98]}\end{array}$ \\
\hline T2 SRS overall & $\begin{array}{l}0.61 \\
{[0.00,0.91]}\end{array}$ & $\begin{array}{l}0.18 \\
{[-0.57,0.84]}\end{array}$ & $\begin{array}{l}0.71^{*} \\
{[0.11,0.98]}\end{array}$ & $\begin{array}{l}0.18 \\
{[-0.49,0.76]}\end{array}$ \\
\hline
\end{tabular}

Values in brackets indicate a 95\% confidence interval for each correlation. For readability, only the nonverbal synchrony behavior groups and/or individual scores for SRS, including significant correlations, are presented

*Indicates $p<0.05$

**Indicates $p<0.01$ 


\section{Appendix 3}

\section{Transcript notations}

\begin{tabular}{|c|c|}
\hline Symbol & Meaning \\
\hline possibly (1) somehow & $\begin{array}{l}\text { Numbers in parentheses represent } \\
\text { pauses in seconds }\end{array}$ \\
\hline think (.) Lisa & $\begin{array}{l}\text { A period in parentheses indicates a } \\
\text { pause of less than } 0.2 \mathrm{~s}\end{array}$ \\
\hline.$h h$ & $\begin{array}{l}\text { Indicates inhalation between } \\
\text { words }\end{array}$ \\
\hline$(($ gestures $))$ & $\begin{array}{l}\text { Double parentheses contain } \\
\text { relevant non-verbal information } \\
\text { added by the transcribers }\end{array}$ \\
\hline$[((T 2$ is in the same... & $\begin{array}{l}\text { Single brackets below the dialogue } \\
\text { indicate the exact moment in } \\
\text { the dialogue when nonverbal } \\
\text { synchrony occurs }\end{array}$ \\
\hline : & $\begin{array}{l}\text { Indicates protracted or extended } \\
\text { pronunciation of a word }\end{array}$ \\
\hline
\end{tabular}

\section{References}

Altmann, U., Schoenherr, D., Paulick, J., Deisenhofer, A.-K., Schwartz, B., Rubel, J. A., et al. (2019). Associations between movement synchrony and outcome in patients with social anxiety disorder: Evidence for treatment specific effects. Psychotherapy Research, 30(5), 574-590. https://doi.org/10.1080/10513 307.2019.1630779

Bailenson, J., Beall, A., Loomis, J., Blascovich, J., \& Turk, M. (2004). Transformed social interaction: Decoupling representation from behavior and form in collaborative virtual environments. Presence: Teleoperators and Virtual Environments, 13, 428-441. https ://doi.org/10.1162/1054746041944803

Baimel, A., Severson, R. L., Baron, A. S., \& Birch, S. A. J. (2015). Enhancing "theory of mind" through behavioral synchrony. Frontiers in Psychology, 6, 870. https://doi.org/10.3389/fpsyg .2015 .00870

Bavelas, J. B., Black, A., Lemery, C. R., MacInnis, S., \& Mullet, J. (1986). Experimental methods for studying "elementary motor mimicry." Journal of Nonverbal Behavior, 10(2), 102-119. https ://doi.org/10.1007/bf01000007

Bernieri, F. J., Reznick, J. S., \& Rosenthal, R. (1988). Synchrony, pseudosynchrony, and dissynchrony: Measuring the entrainment process in mother-infant interactions. Journal of Personality and Social Psychology, 54(2), 243-253. https://doi. org/10.1037/0022-3514.54.2.243

Bordin, E. S. (1979). The generalizability of the psychoanalytic concept of the working alliance. Psychotherapy: Theory Research, and Practice, 16, 252-260. https://doi.org/10.1037/h0085885

Bourgeois, L., Sabourin, S., \& Wright, J. (1990). Predictive validity of therapeutic alliance in group marital therapy. Journal of Consulting and Clinical Psychology, 58(5), 608-613. https://doi. org/10.1037/0022-006X.58.5.608

Chartrand, T. L., \& Bargh, J. A. (1999). The chameleon effect: The perception-behavior link and social interaction. Journal of Personality and Social Psychology, 76(6), 893-910. https://doi. org/10.1037/0022-3514.76.6.893
Chartrand, T. L., \& Lakin, J. L. (2013). The antecedents and consequences of human behavioral mimicry. Annual Review of Psychology, 64, 285-308. https://doi.org/10.1146/annurev-psych-11301 $1-143754$

Cornejo, C., Cuadros, Z., Morales, R., \& Paredes, J. (2017). Interpersonal coordination: Methods, achievements, and challenges. Frontiers in Psychology, 8, 1685. https://doi.org/10.3389/fpsyg .2017 .01685

Davis, M., \& Hadiks, D. (1990). Nonverbal behavior and client state changes during psychotherapy. Journal of Clinical Psychology, 46(3), 340-351. https://doi.org/10.1002/1097-4679(19900 5)46:3\%3c340::aid-jclp2270460315\%3e3.0.co;2-1

Davis, M., \& Hadiks, D. (1994). Nonverbal aspects of therapist attunement. Journal of Clinical Psychology, 50(3), 393-405. https:// doi.org/10.1002/1097-4679(199405)50:3\%3c393::aid-jclp227050 0311\%3e3.0.co;2-t

de Roten, Y., Darwish, J., Stern, D. J., Fivaz-Depeursinge, E., \& Corboz-Warnery, A. (1999). Nonverbal communication and alliance in therapy: The body formation coding system. Journal of Clinical Psychology, 55(4), 425-438. https://doi.org/10.1002/(sici)10974679(199904)55:4\%3c425::aid-jclp7\%3e3.0.co;2-d

de Waal, F. B. M. (2007). The 'Russian Doll' model of empathy and imitation. In S. Bråten (Ed.), On being moved. From mirror neurons to empathy (pp. 49-69). Amsterdam: John Benjamins Publishing Company. https://doi.org/10.1075/aicr.68.06waa.

Duncan, B. L., Miller, S. D., Sparks, J. A., Claud, D. A., Reynolds, L. R., Brown, J., \& Johnson, L. D. (2003). The Session Rating Scale: Preliminary psychometric properties of a "working" alliance measure. Journal of Brief Therapy, 3(1), 3-12.

Friedlander, M. L., Escudero, V., Horvath, A. O., Heatherington, L., Cabero, A., \& Martens, M. P. (2006). System for observing family therapy alliances: A tool for research and practice. Journal of Counseling Psychology, 53(2), 214-225. https://doi. org/10.1037/0022-0167.53.2.214

Friedlander, M. L., Escudero, V., Heatherington, L., \& Diamond, G. M. (2011). Alliance in couple and family therapy. Psychotherapy, 48(1), 25-33. https://doi.org/10.1037/a0022060

Fujiwara, K., \& Daibo, I. (2014). The extraction of nonverbal behaviors: Using video images and speech-signal analysis in dyadic conversation. Journal of Nonverbal Behavior, 38(3), 377-388. https://doi.org/10.1007/s10919-014-0183-3

Gottman, J. M., \& Porterfield, A. L. (1981). Communicative competence in the nonverbal behavior of married couples. Journal of Marriage and Family, 43(4), 817-824. https://doi. org/10.2307/351339

Hall, J. A., Harrigan, J. A., \& Rosenthal, R. (1995). Nonverbal behavior in clinician-patient interaction. Applied \& Preventive Psychology, 4, 21-37. https://doi.org/10.1016/s0962-1849(05)80049-6

Itävuori, S., Korvela, E., Karvonen, A., Penttonen, M., Kaartinen, J., Kykyri, V-L., \& Seikkula, J. (2015). The significance of silent moments in creating words for the not-yet-spoken experiences in threat of divorce. Psychology, 6(11), 1360-1372. https://doi. org/10.4236/psych.2015.611133

Julien, D., Brault, M., Chartrand, É., \& Bégin, J. (2000). Immediacy behaviours and synchrony in satisfied and dissatisfied couples. Canadian Journal of Behavioural Sciences, 32(2), 84-90. https ://doi.org/10.1037/h0087103

Kimura, M., \& Daibo, I. (2006). Interactional synchrony in conversations about emotional episodes: A measurement by "the between participants pseudosynchrony experimental paradigm." Journal of Nonverbal Behavior, 30(3), 115-126. https://doi.org/10.1007/ s10919-006-0011-5

Koole, S. L., \& Tschacher, W. (2016). Synchrony in psychotherapy: A review and an integrative framework for the therapeutic alliance. Frontiers in Psychology, 7, 862. https://doi.org/10.3389/fpsyg .2016 .00862 
Kykyri, V-L., Tourunen, A., Nyman-Salonen, P., Kurri, K., Wahlström, J., Kaartinen, J., et al. (2019). Alliance formations in couple therapy: A multimodal and multimethod study. Journal of Couple \& Relationship Therapy, 18(3), 189-222. https://doi. org/10.1080/15332691.2018.1551166

LaFrance, M. (1985). Postural mirroring and intergroup relations. Personality and Social Psychology Bulletin, 11(2), 207-217. https:// doi.org/10.1177/0146167285112008

Lakens, D., \& Stel, M. (2011). If they move in sync, they must feel in sync: Movement synchrony leads to attributions of rapport and entitativity. Social Cognition, 29(1), 1-14. https://doi. org/10.1521/soco.2011.29.1.1

Lakin, J. L., \& Chartrand, T. L. (2003). Using nonconscious behavioral mimicry to create affiliation and rapport. Psychological Science, 14(4), 334-339. https://doi.org/10.1111/1467-9280.14481

Landis, J. R., \& Koch, G. G. (1977). The measurement of observer agreement for categorical data. Biometrics, 33(1), 159-174. https://doi.org/10.2307/2529310

Louwerse, M. M., Dale, R., Bard, E. G., \& Jeuniaux, P. (2012). Behavior matching in multimodal communication is synchronized. Cognitive Science, 36, 1404-1426. https://doi.org/10.11 11/j.1551-6709.2012.01269.x

Maurer, R. E., \& Tindall, J. H. (1983). Effect of postural congruence on client's perception of counselor empathy. Journal of Counseling Psychology, 30(2), 158-163. https://doi. org/10.1037/0022-0167.30.2.158

Muñiz de la Peña, C. M., Friedlander, M., \& Escudero, V. (2009). Frequency, severity, and evolution of split family alliances: How observable are they? Psychotherapy Research, 19(2), 133-142. https://doi.org/10.1080/10503300802460050

Nagaoka, C., \& Komori, M. (2008). Body movement synchrony in psychotherapeutic counselling: A study using the video-based quantification method. IEICE Transactions on Information and Systems, 91(6), 1634-1640. https://doi.org/10.1093/ietisy/e91-d.6.1634

Nyman-Salonen, P., Vall, B., Laitila, A., Borcsa, M., Penttonen, M., Tourunen, A., et al. (2020). Significant moments in a couple therapy session: Towards the integration of different modalities of analysis. In M. Ochs, M. Borcsa, \& J. Schweitzer (Eds.). Linking systemic research and practice - Innovations in paradigms, strategies and methods. European Family Therapy Association Series (Vol. 5). Cham: Springer. https://doi.org/10.1007/978-3030-36560-8_4

Paulick, J., Deisenhofer, A. K., Ramseyer, F., Tschacher, W., Boyle, K., Rubel, J., \& Lutz, W. (2018). Nonverbal synchrony: A new approach to better understand psychotherapeutic processes and drop-out. Journal of Psychotherapy Integration. https://doi. org/10.1037/int0000099

Raingruber, B. J. (2001). Settling into and moving in a climate of care: Styles and patterns of interaction between nurse psychotherapist and clients. Perspectives in Psychiatric Care, 37(1), 15-27. https://doi.org/10.1111/j.1744-6163.2001.tb00612.x
Ramseyer, F. T. (2020). Exploring the evolution of nonverbal synchrony in psychotherapy: The idiographic perspective provides a different picture. Psychotherapy Research, 30(5), 622-634.

Ramseyer, F., \& Tschacher, W. (2011). Nonverbal synchrony in psychotherapy: Coordinated body movement reflects relationship quality and outcome. Journal of Consulting and Clinical Psychology, 79(3), 284-295. https://doi.org/10.1037/a0023419

Ramseyer, F., \& Tschacher, W. (2014). Nonverbal synchrony of headand body-movement in psychotherapy: Different signals have different association with outcome. Frontiers in Psychology, 5, 1-9. https://doi.org/10.3389/fpsyg.2014.00979

Seikkula, J., Karvonen, A., Kykyri, V-L, Kaartinen, J., \& Penttonen, M. (2015). The embodied attunement of therapists and a couple within dialogical psychotherapy: An introduction to the relational mind research project. Family Process, 54(4), 703-715. https:// doi.org/10.1111/famp.12152

Sharpley, C. F., Halat, J., Rabinowicz, T., Weiland, B., \& Stafford, J. (2001). Standard posture, postural mirroring and client-perceived rapport. Counseling Psychology Quarterly, 14(4), 267-280. https ://doi.org/10.1080/09515070110088843

Sonnby-Borgström, M. (2002). Automatic mimicry reactions as related to differences in emotional empathy. Scandinavian Journal of Psychology, 43, 433-443. https://doi.org/10.1111/1467-9450.00312

Sonnby-Borgström, M., \& Jönsson, P. (2003). Emotional empathy as related to mimicry reactions at different levels of information processing. Journal of Nonverbal Behavior, 27(1), 3-23. https://doi. org/10.1023/A:1023608506243

Stel, M., \& Vonk, R. (2010). Mimicry in social interaction: Benefits for mimickers, mimickees, and their interaction. British Journal of Psychology, 101, 311-323. https://doi.org/10.1348/000712609x 465424

Symonds, D., \& Horvath, A. O. (2004). Optimizing the alliance in couple therapy. Family Process, 43(4), 443-455. https://doi.org/ 10.1111/j.1545-5300.2004.00033.x

Tickle-Degnen, L., \& Rosenthal, R. (1990). The nature of rapport and its nonverbal correlates. Psychological Inquiry, 1(4), 285-293. https://doi.org/10.1207/s15327965pli0104_1

Trout, D. L., \& Rosenfeld, H. M. (1980). The effect of postural lean and body congruence on the judgment of psychotherapeutic rapport. Journal of Nonverbal Behavior, 4(3), 176-190. https://doi. org/10.1007/bf00986818

Vicaria, I. M., \& Dickens, L. (2016). Meta-analyses of the intra- and interpersonal outcomes of interpersonal coordination. Journal of Nonverbal Behavior, 40(4), 335-361. https://doi.org/10.1007/ s10919-016-0238-8

Wang, M. (2014). Generalized estimating equations in longitudinal data analysis: A review and recent developments. Advances in Statistics. https://doi.org/10.1155/2014/303728

Publisher's Note Springer Nature remains neutral with regard to jurisdictional claims in published maps and institutional affiliations. 